\title{
Polymicrobial and monomicrobial necrotizing fasciitis: clinical, laboratory, radiology, pathological hallmark and differences, a retrospective analysis
}

\section{Eviatar Naaman}

Tel Aviv University Sackler Faculty of Medicine

Shachaf Shiber ( $\sim$ sofereret@gmail.com )

Rabin Medical Center https://orcid.org/0000-0001-6160-0075

Daskin-Bitan Hadar

Rabin Medical Center

Dafna Yahav

Rabin Medical Center

Jihad Bishara

Rabin Medical Center

Iftach Sagy

Soroka Hospital: Soroka Medical Center

Nadav Granat

Rabin Medical Center

Micheal Drescher

Rabin Medical Center

\section{Research}

Keywords: Necrotizing fasciitis, mono-bacterial, poly-bacterial, antibiotic treatment

Posted Date: April 8th, 2021

DOI: https://doi.org/10.21203/rs.3.rs-264532/v2

License: (1) (1) This work is licensed under a Creative Commons Attribution 4.0 International License. Read Full License 


\section{Abstract}

Background: Necrotizing fasciitis (NF) is a life-threatening infection with high morbidity and mortality rates which should be diagnosed and treated with surgical and antibiotic therapy. Many studies have addressed NF and its subtypes, but few have reviewed the clinical, radiological and pathological differences between the poly-microbial and the mono-microbial groups.

Objective: The objective of our study is to describe a relatively large cohort of patients with NF and study and compare the clinical, radiological and pathological differences between the poly-microbial $(\mathrm{Pm})$ and the mono-microbial $(\mathrm{Mm})$ groups.

Methods: The charts of hospitalized patients with NF diagnosis from 2002-2019 at the Rabin Medical Center were reviewed. The primary outcome was all-cause mortality at 90 days, secondary outcomes included duration of hospitalization, intensive care unit (ICU) admission, LRINEC score and the need for vasopressor use.

Results: 81 patients with NF were included in the study, 54(66.6\%) had Mm growth and 27(33.3\%) had Pm growth. There were no significant differences between the two groups in the 90 days mortality, and moreover in hospital mortality was also insignificantly different. In a multivariate analysis, we found that 90 days mortality was more prevalent in the Mm group compared to Pm group. In addition, we found that in hospital mortality, ICU admission and vasopressors use were more frequent among the Mm-group compared to the Pm-group.

Conclusions: our study is the first to compare the differences between the two most prevalent entities of NF. The results demonstrate better prognosis for Pm-NF, with minimal ICU stay, lower mortality, and lower use of vasopressors.

\section{Key Messages}

What is already known on this subject -

Necrotizing fasciitis (NF) is a life-threatening infection with high morbidity and mortality rates.

This medical emergency should be diagnosed and treated with surgical and antibiotic therapy.

What this study adds

Our study is the first to compare the differences between the monobacterial and polybacterial NF, two most prevalent entities of NF.

The results demonstrate better prognosis for Polymicrobial NF, with minimal ICU stay, lower mortality, and lower use of vasopressors. 


\section{Background}

Necrotizing fasciitis (NF) is an infrequent fatal soft tissue infection first described by Jones [1] in 1871. The annual incidence of Necrotizing fasciitis in the US [2] is 0.04 per 1000 person years, and varies between different populations [3]. The mortality rate due to NF is high, ranging from $30 \%-70 \%[4,5]$, thus making early diagnosis crucial for the reduction of morbidity and mortality.

$\mathrm{NF}$ is divided into several subtypes shown below, based upon the microbiological profiles of the infection, with the first two being the most frequent.

Type I NF, is a poly-microbial infection involving aerobic and anaerobic organisms, its incidence is still debatable. Some studies have found type I to be the most prevalent, accounting for almost $80 \%$ of all necrotizing soft tissue infections (NSTI) [5-7], while others found it to be responsible for $30-55 \%$ of all NST I8-9]]. Predisposing factors for type I include diabetic ulcers, hemorrhoids, and rectal fissures. Gas in the tissue is often a sign correlated with type $1 \mathrm{NF}$ [10].

Type II NF contributes $10 \%-40 \%$ of NSTI [8, 9] and is usually caused by a Gram positive mono-microbial infection, the most common being Group A Streptococcus. $[3,11]$, followed by Staphylococcus aureus [10, 11]. Type II NF may occur in all age groups and among individuals with no comorbidities [12].

Other types of NF are rather scarce and their definition is still debated.

Type III NF is characterized by some as a clostridial infection caused by the clostridia [13], while other define Type III as mono-microbial infection primarily caused by Vibrio Spp [14].

Type IV NF caused by fungal infection and occurring mostly after traumatic wounds and burns, with Aspergillus and zygomycetes being the most frequent causative organisms [14].

Mono-microbial NF caused by Gram negative bacteria has been reported more frequently in recent years [15-17], and it is an emerging cause of NF. Several studies have found that mono-microbial Gramnegative bacteria account for ca. $50 \%$ of the mono-microbial NF cases, with the predominant causative organisms being Klebsiella pneumonia [18], and Escherichia coli. [16, 17, 19]. A higher 30 day mortality rate was attributed to Gram negative mono-microbial NF as opposed to Gram positive mortality rate (42.1\% vs $30.8 \%$ respectively) [17].

While many studies have addressed necrotizing fasciitis and its subtypes, only a few have reviewed the clinical, radiological and pathological differences between the types. The aim of our research is to study a relatively large cohort of patients with NF and compare the clinical, radiological and pathological differences between the poly-microbial and mono-microbial groups.

\section{Methods}


The charts of all hospitalized patients with NF diagnosis (screening for ICD-10 NF related codes including m72.6) [20] between 2002 to 2019 at the Rabin Medical Center were reviewed.

The diagnosis of NF was confirmed for all patients with intraoperative clinical findings such as presence of necrotic fascia, purulent discharge and/or histopathologic verification supporting the diagnosis. Aerobic and anaerobic cultures were obtained for all patients from both the blood and the soft infected tissues prior to the antibiotic treatment.

All blood and tissue cultures were processed at the microbiology laboratory at Rabin Medical Center. Bacterial identification and susceptibility testing were done by routine methods. Until 2012 all isolations were performed by manual biochemical testing, followed by VITEK-II in inconclusive cases. As of 2012 all isolations were verified by either MALDI-TOF or VITEK-II. Susceptibility tests were performed using disk diffusion and E-test methods and interpreted according to CLSI criteria.

Positive culture was defined as the isolation of a bacterial pathogen from at least one blood culture and/or infected soft tissue (obtained intraoperative or by skin biopsy) and evidence of necrotic fascia during an operation or pathology features consistent with the diagnosis (extensive tissue destruction, thrombosis of blood vessels, abundant bacteria spreading along fascial planes, and infiltration of acute inflammatory cells) [21].

For patients who have not undergone surgery, a culture was diagnosed and considered positive with the isolation of a bacterial pathogen and high clinical suspicion based on systemic clinical signs, soft tissue involvement and clinical manifestation.

The patients were assigned into two groups according to the NF classification, Group I was consistent with Type 1 NF and included patients with Polymicrobial infection (Pm group) and group 2 included type II NF based on the mono-microbial (Mm group) growth. Although type $3 \mathrm{NF}$ is considered to be caused by mono-microbial organisms, our study found that all the causative mono-microbial organisms to belonged to type II NF, hence group 2 is equal in our study to Type II NF.

Clinical and laboratory data collected for all patients at presentation included fever, blood pressure, heart rate, white blood cells count, platelet count, C-reactive protein, creatinine, serum glucose levels, lactate, creatinine kinase (CK), albumin, and sodium.

Imaging, clinical examination, number of surgeries, duration of hospitalization, intensive care unit (ICU), amputation, use of vasopressors, death date data and Charlson comorbidity index were also collected [22].

The modified Chralson comorbidity index (CCl) predicts 10 years survival in patients. This index is in practice to assess patient comorbidity risk and consists of 9 different comorbidities.

All patients had their medical record checked for surgeries, related anatomically to the infection site, which were performed in the last 30 days 
In order to assess sepsis severity, quick SOFA (qSOFA) score was calculated upon admission to the hospital. qSOFA score was first introduced in 2016, and was validated internally and externally for predicting mortality in patients diagnosed with sepsis. qSOFA Score $\geq 2$ suggests high risk of poor outcome (in a scale of $0-3$ ) $[23,24]$.

In addition, immunosuppression status was collected for all patients. Positive immunosuppression status was determined when patients were receiving more the $20 \mathrm{mg}$ prednisone and or cytotoxic drug/chemotherapy.

LRINEC score is in use to distinguish patients with severe cellulitis or abscess vs necrotizing fasciitis. LRINEC score includes the following laboratory data: C-reactive protein, WBC, $\mathrm{Hb}, \mathrm{Na}$, creatinine and glucose, a score equal or above is the agreed cut off to rule-in NF. We used the LRINEC score, for laboratory risk assessment [25]. In order to assess the severity of the NF, we calculated in our study the LRINEC score at admission to the Emergency Department (ED) for all patients.

The study protocol was approved by the local ethics committee.

The primary outcome was all-cause mortality at 90 days. Secondary outcomes included length of hospitalization, intensive care unit (ICU) admission, LRINEC score and the need for vasopressor use, and amputation by 90 days. We compared for these outcomes the poly-microbial group with the monomicrobial one.

\section{Statistics}

Data are expressed as means \pm standard deviations (SD), median \pm interquartile range (IQR), or number and percentage. We compared patient characteristics between poly vs. mono bacterial groups using ttest, chi-square and non-parametric tests. To estimate the association of the study outcomes with type of bacterial growth, we conducted a forward stepwise logistic regression of the dependent variable. Each set of covariates (demographic, medical history, laboratory, etc.) was entered as separate block to the model. The final model was selected based on model goodness of fit using the c-statistic and plausible clinical explanation. For the primary outcome of 90 days mortality, we used Cox regression, using the same stepwise method described above. Data analysis was performed using SPSS version 25.0.

\section{Results}

Eighty-one patients with NF were included in the study, 54 (66.6\%) had mono-microbial growth and 27 (33.3\%) had poly-microbial growth. All patients in our cohort had a bacterial growth, from blood infection or wound infection, or both. Gram-positive bacteria were the most common group of pathogens in the mono-microbial group $(31 / 54,57.4 \%)$, with Streptococcus pyogenes being the most common pathogen isolated $(18 / 54,33.3 \%)$. 
Among the Gram-negative bacteria causing Mm NF, E.coli was the most common one, isolated in 7 cases (7/22, 13\%). In the Pm group, Gram-negatives predominated (38/54 (70\%)), with E.colibeing the most common pathogen (17 (31.5\%) isolations). Table 1 depicts all pathogen isolations, it should be noted that some patients had simultaneously several bacterial isolations; hence, the number of isolations depicted in Table 1 is larger than the number of patients.

Table 1

Pathogens associated with NF

\begin{tabular}{|c|c|c|c|}
\hline $\begin{array}{l}\text { Gram stain } \\
\text { ( } \mathrm{n}, \% \text { of } \\
\text { isolations) }\end{array}$ & Pathogen & $\begin{array}{l}\text { Mono-microbial }(n= \\
54)\end{array}$ & $\begin{array}{l}\text { Poly-microbial }(n= \\
\text { 58) }\end{array}$ \\
\hline \multirow[t]{9}{*}{ Positive } & Streptococcus pyogenes & $18(33.3)$ & $1(1.7)$ \\
\hline & Streptococcus pneumoniae & 0 & $1(1.7)$ \\
\hline & Streptococcus group F & $1(1.9)$ & $1(1.7)$ \\
\hline & Streptococcus viridans & 0 & $3(5)$ \\
\hline & Streptococcus group B & $6(11.1)$ & $1(1.7)$ \\
\hline & Staphylococcus aureus & $6(11.1)$ & $4(7)$ \\
\hline & $\begin{array}{l}\text { Staphylococcus coagulase } \\
\text { negative }\end{array}$ & 0 & $2(4)$ \\
\hline & Enterococcus spp & 0 & $7(13)$ \\
\hline & Total & $31(57.4)$ & $20(34)$ \\
\hline \multirow[t]{9}{*}{ Negative } & Pseudomonas aeruginosa & $4(7.4)$ & $4(7)$ \\
\hline & Escherichia coli & $7(13.0)$ & $17(31.5)$ \\
\hline & Enterobacter cloacae & $1(1.9)$ & $1(1.7)$ \\
\hline & Proteus mirabilis & $2(3.7)$ & $5(8)$ \\
\hline & Serratia marcescens & $1(1.9)$ & 0 \\
\hline & Klebsiella pneumonia & $2(3.7)$ & $5(8)$ \\
\hline & Acinetobacter baumannii & $3(5.6)$ & $6(11)$ \\
\hline & Aeromonas hydrophila & $2(3.7)$ & 0 \\
\hline & Total & $22(40.7)$ & $38(70)$ \\
\hline
\end{tabular}

Table 2 lists the epidemiological characteristic of our cohort. We use the qSOFA to assess sepsis severity and found no significant differences between the Mm and Pm groups ( $1.67 \pm 0.9$ vs. $1.56 \pm 0.9$ mean + $S D, p=0.64$, respectively). 
Table 2

General characteristics of the study cohorts

\begin{tabular}{|c|c|c|c|}
\hline Variable & Mono-microbial $(n=54)$ & Poly-microbial ( $n=27$ ) & $P$ value \\
\hline Gender, males n (\%) & $27(50.0)$ & $10(37.0)$ & 0.34 \\
\hline Age $($ mean $\pm S D)$ & $62.1(15.7)$ & $59.4(20.0)$ & 0.50 \\
\hline Admitted from home, n (\%) & $42(77.8)$ & $13(65.0)$ & 0.36 \\
\hline $\begin{array}{l}\text { Weighted Charlson's index, median } \\
\text { (i.q range) }\end{array}$ & $3.0(1.0-5.0)$ & $4.0(1.7-7.0)$ & 0.23 \\
\hline qSOFA score (mean \pm SD) & $1.67(0.9)$ & $1.56(0.9)$ & 0.6 \\
\hline \multicolumn{4}{|l|}{ Etiology } \\
\hline Post surgery, n (\%) & $18(47.4)$ & $4(16.7)$ & \multirow[t]{3}{*}{0.02} \\
\hline Trauma, n (\%) & $6(15.8)$ & $3(12.5)$ & \\
\hline Soft tissue infection, n (\%) & $14(36.8)$ & $17(70.8)$ & \\
\hline Previous IV catheter, n (\%) & $3(5.6)$ & $7(25.9)$ & 0.01 \\
\hline Any port of entry, n (\%) & $29(53.7)$ & $20(76.9)$ & 0.05 \\
\hline $\mathrm{BMI}>25$ & $10(18.5)$ & $19(40.4)$ & $<0.001$ \\
\hline Immunosuppression, n (\%) & $17(31.5)$ & $3(11.1)$ & 0.06 \\
\hline
\end{tabular}

Our study found a significant difference between the two groups in terms of post-surgery rates, while only $16.7 \%$ of the Pm group had undergone surgery in the last 30 days, almost $50 \%$ of the patients in the $\mathrm{Mm}$ group had undergone surgery in the last 30 days. $(p=0.02)$.

Clinical findings like redness and swelling were significantly more common in the Mm group $(p=0.04, p=$ $0.01)$, whereas confusion was more common in the Pm group $(p=0.04)$ (Table 3$)$. Laboratory values were similar for the Mm and Pm groups. With CK at normal range in both groups (Table 4). 
Table 3

Clinical characteristics and vital signs of patients cohort

\begin{tabular}{|llll|}
\hline Variable & \begin{tabular}{l} 
Mono-microbial $\left(\mathbf{n}=\begin{array}{l}\text { Poly-microbial }(\mathbf{n}=\mathbf{P} \\
\mathbf{2 7})\end{array}\right.$ \\
\hline Clinical presentation
\end{tabular} & $\begin{array}{l}\mathbf{P} \\
\text { value }\end{array}$ \\
\hline Fever, ${ }^{8 \mathrm{C}} \mathrm{n}(\%)$ & $18(33.3)$ & $10(37.0)$ & 0.80 \\
\hline Pain, $\mathrm{n}(\%)$ & $29(53.7)$ & $20(74.1)$ & 0.09 \\
\hline Redness, $\mathrm{n}(\%)$ & $15(27.8)$ & $2(7.4)$ & 0.04 \\
\hline Swelling, $\mathrm{n}(\%)$ & $17(31.5)$ & $1(3.7)$ & 0.01 \\
\hline Confusion, $\mathrm{n}(\%)$ & $4(7.4)$ & $7(25.9)$ & 0.04 \\
\hline Septic shock, $\mathrm{n}(\%)$ & $33(61.1)$ & $11(40.7)$ & 0.10 \\
\hline Limbs location*, $\mathrm{n}(\%)$ & $30(55.6)$ & $7(29.5)$ & 0.02 \\
\hline Heart rate bpm (mean \pm SD) & $92.5(22.4)$ & $98.3(22.6)$ & 0.29 \\
\hline $\begin{array}{l}\text { Mean Blood Pressure mmHg } \\
\text { (mean } \pm \text { SD) }\end{array}$ & $82.3(17.1)$ & $82.4(16.4)$ & 0.97 \\
\hline LRINEC score, median (i.q range) & $7.0(5.0-9.0)$ & $7.7(6.0-10.0)$ & 0.29 \\
\hline
\end{tabular}


Table 4

Laboratory characteristics and vital signs of patient's cohort

\begin{tabular}{|c|c|c|c|}
\hline Variable & Mono-microbial $(n=54)$ & Poly-microbial $(n=27)$ & $P$ value \\
\hline Hemoglobin g/dl (mean \pm SD) & $10.1(2.0)$ & $9.6(1.9)$ & 0.38 \\
\hline $\mathrm{WBC}^{\&} \times 10^{9} / \mathrm{I}($ mean $\pm \mathrm{SD})$ & $14.1(9.5)$ & $18.8(6.8)$ & 0.03 \\
\hline Platelets $\mathrm{X} 10^{9} / \mathrm{I}($ mean $\pm \mathrm{SD})$ & $229.9(122.3)$ & $346.9(146.1)$ & $<0.001$ \\
\hline $\mathrm{CRP}^{\wedge} \mathrm{mg} / \mathrm{dl}($ mean $\pm \mathrm{SD})$ & $27.2(16.1)$ & $27.2(11.1)$ & 0.99 \\
\hline Creatinine $\mathrm{mg} / \mathrm{dl}($ mean $\pm \mathrm{SD}$ ) & $1.9(2.2)$ & $1.2(0.7)$ & 0.06 \\
\hline Glucose meq/I (mean \pm SD) & $177.4(117.9)$ & $168.5(89.6)$ & 0.73 \\
\hline Lactate mg/dl (mean \pm SD) & $24.4(15.5)$ & $26.6(17.4)$ & 0.61 \\
\hline $\mathrm{CK}^{\$} \mathrm{mg} / \mathrm{dl}$, median (i.q range) & $149(33-464)$ & $58(18-172)$ & 0.68 \\
\hline Albumin (mean $\pm S D$ ) & $2.7(0.8)$ & $2.5(0.7)$ & 0.18 \\
\hline Natrium meq/I (mean \pm SD) & $135.1(5.0)$ & $134.5(4.8)$ & 0.62 \\
\hline \multicolumn{4}{|l|}{ \& white blood cell } \\
\hline${ }^{\wedge} \mathrm{C}-$ reactive protein & & & \\
\hline
\end{tabular}

Radiographic features in CT were different in the two groups, with statistically significant features of more free air and fat infiltrate findings in the PM group ( $p=0.002$ and $p=0.002$, respectively). In pathology examination, we also found different features in the PM group, with statistically significant more extensive tissue destruction and infiltration of inflammatory cells in tissue biopsy among the $\mathrm{Mm}$ group. $(p=0.003$ and $p=0.01$, respectively) (Table 5). 
Table 5

Radiographic and pathologic characteristics of patients cohort

\begin{tabular}{|llll|}
\hline Variable & $\begin{array}{l}\text { Mono-microbial }(\mathrm{n}= \\
\mathbf{5 4})\end{array}$ & Poly-microbial $(\mathrm{n}=\mathbf{2 7})$ & P value \\
\hline CT features & & $20(80.0)$ & 0.02 \\
\hline Free air, $\mathrm{n}(\%)$ & $20(48.8)$ & $14(56.0)$ & 0.13 \\
\hline Edema, $\mathrm{n}(\%)$ & $15(36.6)$ & $10(40.0)$ & 0.16 \\
\hline Collection, $\mathrm{n}(\%)$ & $9(22.0)$ & $20(80.0)$ & 0.002 \\
\hline Fat infiltrate, $\mathrm{n}(\%)$ & $16(39.0)$ & $2(8.0)$ & 0.09 \\
\hline Liquefaction, $\mathrm{n}(\%)$ & $10(24.4)$ & & 0.003 \\
\hline Pathology features & & $10(100.0)$ & 0.39 \\
\hline Extensive tissue destruction, $\mathrm{n}(\%)$ & $23(47.9)$ & $0(0.0)$ & 0.91 \\
\hline Thrombosis, $\mathrm{n}(\%)$ & $3(6.3)$ & $1(9.1)$ & 0.01 \\
\hline Abundant bacterial spreading, $\mathrm{n}(\%)$ & $5(10.2)$ & $10(90.9)$ & \\
\hline $\begin{array}{l}\text { Infiltration of inflammatory cells, } \mathrm{n} \\
\text { (\%) }\end{array}$ & $22(44.9)$ & & \\
\hline
\end{tabular}

The results regarding the clinical outcomes are shown in Table 6. In the primary outcome (90 days mortality) there were no significant difference between the two groups. However, the length of hospitalization period was higher among the PM group patients than among the Mm group patients (32.8 $(12.0-45.0)$ vs. $23.5(12.7-42.0), p=0.04)$. The numbers of surgical interventions by 90 days were higher and more common in the PM groups as compared to the Mm group (3.0 (2.0-4.0) vs. $1.5(1.0-3.0), p=$ 0.04 , respectively). 
Table 6

Outcomes of patient's cohort

\begin{tabular}{|c|c|c|c|}
\hline Variable & $\begin{array}{l}\text { Mono- } \\
\text { microbial ( } \mathrm{n} \\
=54 \text { ) }\end{array}$ & $\begin{array}{l}\text { Poly- } \\
\text { microbial (n } \\
=27 \text { ) }\end{array}$ & $\begin{array}{l}\mathrm{P} \\
\text { value }\end{array}$ \\
\hline Mortality 90 days, $\mathrm{n}(\%)$ & $26(48.1)$ & 9 (33.3) & 0.24 \\
\hline In hospital mortality, n (\%) & $22(40.7)$ & $7(25.9)$ & 0.22 \\
\hline Length of ICU stay, median days (i.q range) & $4.5(0.0-15.7)$ & $0.0(0.0-4.5)$ & 0.81 \\
\hline Length of total hospitalization, median days (i.q range) & $\begin{array}{l}23.5(12.7- \\
42.0)\end{array}$ & $\begin{array}{l}32.8(12.0- \\
45.0)\end{array}$ & 0.04 \\
\hline Mechanical ventilation, $\mathrm{n}(\%)$ & $31(62.0)$ & $11(50.0)$ & 0.43 \\
\hline Vasso-pressors, n (\%) & $27(65.9)$ & $7(35.0)$ & 0.03 \\
\hline Amputations 90 days, $\mathrm{n}(\%)$ & $5(9.3)$ & $5(18.7)$ & 0.23 \\
\hline $\begin{array}{l}\text { Any surgery (including amputation and debridment of the } \\
\text { involving site) } 90 \text { days, median (i.q range) }\end{array}$ & $2(0-10)$ & $3(0-6)$ & 0.056 \\
\hline Number of surgical interventions 90 days, $\mathrm{n}(\%)$ & $1.5(1.0-3.0)$ & $\begin{array}{l}3.0(2.0- \\
4.0)\end{array}$ & 0.04 \\
\hline
\end{tabular}

In a multivariate analysis for clinical outcomes between the Mm and PM groups, adjusted for age and sex, we found that 90 days mortality was more prevalent in the Mm groups compared to the Pm group (Table 7). In addition, we found that in hospital mortality, ICU admission and vasopressors use were more frequent among the Mm groups compared to the Pm group.

Table 7

Multivariate logistic regression of clinical outcomes and bacterial type*

\begin{tabular}{|c|c|c|c|}
\hline Outcome & $P$ value & Odds ratio & 95\% C.I \\
\hline In hospital mortality & 0.05 & 0.30 & $0.95-0.99$ \\
\hline Mortality 90 days & 0.04 & 0.31 & $0.10-0.96$ \\
\hline ICU admission & 0.05 & 0.34 & $0.11-0.99$ \\
\hline Mechanical ventilation & 0.24 & 0.51 & $0.17-1.56$ \\
\hline Vasso-pressors & 0.02 & 0.21 & $0.06-0.75$ \\
\hline \multicolumn{4}{|c|}{ *Reference is mono-microbial } \\
\hline & & & \\
\hline
\end{tabular}

In Fig. 1 of in-hospital mortality stratified by microbial type, we found that more patients in the Pm group survived longer at day 60 compared to the Mm group $(p=0.25)$, however this finding did not differ significantly. 


\section{Discussion}

This is the first study comparing the presentation, treatment and prognosis of patients with Mm vs. Pm NF. We aimed to find and describe the differences between the types of NF; so that the study will shed new information and will show ways to achieve a faster diagnosis of this clinical devastating infection.

Our study found clinical and radiological differences at presentation in those groups. Redness and swelling in the site of infection were significantly more common in the Mm group whereas non-specific findings (confusion) were more common in the Pm group. In line with previous studies, overweight patients were at risk for necrotizing soft tissue infections in general and more likely to have polymicrobial than mono-microbial infections [26].

The clinical differences which we found between the groups are in accordance with the current literature [26-28], where Mm NF, especially strep group A pathogens, are often located in the extremities and in more exposable places, while Pm NF is more complex and causes deeper infections (involving the perineum, sacrum) where redness and swelling cannot be seen. Pain was common in both groups and it is typical for NF to see pain that is non-proportional to findings in the physical examination.

Several radiological findings in our study were overlapping in both groups. Among those non-specific findings we noticed fluid collection, edema, and liquefaction. Our findings correlate with the current radiological pattern for NF which usually includes with fluid collections along the deep fascial sheaths, a non-enhancement of the muscular fascia and extension of edema into the intramuscular septa, vascular thrombosis, subcutaneous gas, fluid collections along the deep fascial sheaths, low attenuation areas in the deeper fascial planes suggestive of fat infiltrate and liquefaction necrosis, with facial involvement and lack of fascial enhancement being the most indicative signs for NF [20].

In our study, the CT findings were consistent with the literature [30-31]; free air cases in the tissue were more common in the Pm group, reflecting the anaerobic component causing this finding. [32]

When checking NF outcomes, we found that there were lower ICU hospitalization, lower use of vasopressors, and lower in hospital mortality rates among the Pm group compared to the Mm group. Several studies have found that the Mm NF due to gram negative bacteria is associated with higher mortality rates [33-34]. Group B Streptococcus NF infections were also previously described as associated with higher mortality rates [25]. Our Mm group included six cases of NF caused by group B Streptococcus. Still, historically group A Streptococcus accounts for most of the group, and the higher mortality rate found in our study among the Mm group could be attributed to an epidemiological shift of invasive GAS strains as was described in Sweden $[26,35]$.

Our analysis found a higher rate of surgical interventions performed on the Pm group compared to the Mm group. This finding has not been described previously in the literature. While it could explain the higher mortality rate among the Mm group, we think that the distinct radiographic features among the Pm 
group patients lead to prompt surgical intervention and to subsequent interventions following early intervention.

Although not statistically significant, our analysis found overall mortality to be lower among the $\mathrm{Pm}$ group compared to the Mm group. A possible explanation of the lower mortality could be due to the fact that the poly-microbial group underwent significantly more surgeries than the mono-microbial group, and this finding could account for the mortality differences between the groups.

Limitation: our study has several limitations. First, NF is a rare disease; hence, the number of cases in this cohort is small, however - most of the published studies dealing with NF are of the same size. Secondly, the retrospective nature of this study limits us to the available medical records, hence, decision-making data on the reasons why some patients underwent more surgeries than others did, and on the nature of the medical treatments including ventilation support, hemodynamic support and antibiotic treatment, are not noted. Our study is based on the medical charts, filled by medical staff, it is possible that there were some mistakes; however, it is unlikely that such errors would have occurred more often in a particular group.

In conclusion, our study is the first to compare the differences between the two most prevalent entities of NF. The results demonstrate better prognosis for Pm NF, with minimal ICU stay, lower mortality, and lower use of vasopressors. As discussed above, those findings could be due to the radiological characteristics which make Pm NF unique and thus its diagnosis is not delayed. But it is also possible that the presentation of the majority of the Pm group with skin and soft tissue infections helped the physician reach a quicker diagnosis. Either way, those results require further investigation to assess their true impact. We believe that identifying the unique features of each entity can be helped by prompt and accurate diagnosis, and by elucidating the best treatment for each entity; thus additional studies are required in order to achieve these objectives.

\section{Declarations}

Ethics approval and consent to participate - The research have been performed in accordance with the Declaration of Helsinki and approved by an appropriate ethics committee: Beilinson hospital helsinky board, Number: IRB - 17-194

Consent for publication - N/A

Availability of data and materials - The datasets used and/or analysed during the current study are available from the corresponding author on reasonable request.

Competing interests - none

Funding - no funding 
Authors' contributions - EN, HDB, SS recorded patients characteristics. SS, JB ,DY wrote the manuscript. IS, NG conducted the statistics, MD review the written manuscript and edit it.

Acknowledgements - none

\section{References}

1. Jones J. Surgical memoirs of the war of the rebellion: investigation upon the nature, causes and treatment of hospital gangrene as prevailed in the Confederate armies 1871;60-65.

2. Ellis Simonsen SM, Van Orman ER, Hatch BE, et al. Cellulitis incidence in a defined population. Epidemiol Infect 2006; 134(2):293-9.

3. Khamnuan $P$, Chongruksut $W$, Jearwattanakanok $K$, et al. Necrotizing fasciitis: Epidemiology and clinical predictors for amputation. Int J Gen Med 2015; 8: 195-202.

4. Adams EM, Gudmundsson S, Yocum DE, et al. Streptococcal Myositis. Arch Intern Med 1985; 145(6):1020-3.

5. McHenry CR, Piotrowski JJ, Petrinic D, et al. Determinants of mortality for necrotizing soft-tissue infections. In: Annals of Surgery 1995; 221(5):558 - 63.

6. Van Stigt SFL, De Vries J, Bijker JB, et al. Review of 58 patients with necrotizing fasciitis in the Netherlands. World J Emerg Surg 2016; 27;11:21.

7. Giuliano A, Lewis F, Hadley K, et al. Bacteriology of necrotizing fasciitis. Am J Surg 1977; 134(1):52 7.

8. Dworkin MS, Westercamp MD, Park $L$, et al. The epidemiology of necrotizing fasciitis including factors associated with death and amputation. Epidemiol Infect 2009; 137(11):1609-14.

9. Wong $\mathrm{CH}$, Chang HC, Pasupathy $S$, et al. Necrotizing fasciitis: Clinical presentation, microbiology, and determinants of mortality. J Bone Jt Surg - Ser A 2003; 85(8):1454-60.

10. Stevens DL, Bryant AE. Necrotizing soft-tissue infections. New England Journal of Medicine 2017; 377(23):2253-2265.

11. Machado NO. Necrotizing fasciitis: The importance of early diagnosis, prompt surgical debridement and adjuvant therapy. North American Journal of Medical Sciences 2011; 27(12):1195-9.

12. O'Loughlin RE, Roberson A, Cieslak PR, et al. The Epidemiology of Invasive Group A Streptococcal Infection and Potential Vaccine Implications: United States, 2000-2004.Clin Infect Dis 2007; $45(7): 853-62$.

13. Ustin JS, Malangoni MA. Necrotizing soft-tissue infections. Critical Care Medicine 2011; 12(1): $77-81$.

14. Morgan MS. Diagnosis and management of necrotising fasciitis: A multiparametric approach. Journal of Hospital Infection 2010; 75(4):249 - 57.

15. Kulasegaran $S$, Cribb $B$, Vandal $A C$, et al. Necrotizing fasciitis: 11-year retrospective case review in South Auckland. ANZ J Surg 2016; 86(10):826-830. 
16. Tsai YH, Shen SH, Yang $T Y_{\text {, }}$ et al. Monomicrobial Necrotizing Fasciitis Caused by Aeromonas hydrophila and Klebsiella pneumoniae. Med Princ Pract 2015; 24(5):416 - 23.

17. Yahav D, Duskin-Bitan H, Eliakim-Raz N, et al. Monomicrobial necrotizing fasciitis in a single center. The emergence of Gram-negative bacteria as a common pathogen. Int J Infect Dis 2014; 28:13 - 6 .

18. Cheng NC, Yu YC, Tai HC, et al. Recent trend of necrotizing fasciitis in taiwan: Focus on monomicrobial Klebsiella pneumoniae necrotizing fasciitis. Clin Infect Dis 2012; 55(7):930-9.

19. Chang chien $\mathrm{CH}$, Chen $Y Y$, Chen SW, et al. Retrospective study of necrotizing fasciitis and characterization of its associated Methicillin-resistant Staphylococcus aureus in Taiwan. BMC Infect Dis 2011; 31;11:297.

20. https://icd.who.int/browse10/2016/en\#/M72.6.

21. Lancerotto L, Tocco I, Salmaso R, et al. Necrotizing fasciitis: Classification, diagnosis, and management. Journal of Trauma and Acute Care Surgery 2012; 72(3):560-6.

22. Charlson ME, Pompei $P$, Ales $K L$, et al. A new method of classifying prognostic comorbidity in longitudinal studies. Development and validation. J Chronic Dis 1987; 40(5):373 - 83

23. Moskowitz APP, Grossestreuer AV, Chase M, et al. qSOFA and SIRS as Predictors of Critical Care Intervention among Patients with Suspected Infection. Critical Care Medicine 2017; 45(11): 1813.

24. Shankar-Hari M, Phillips GS, Levy ML, et al. Developing a New Definition and Assessing New Clinical Criteria for Septic Shock. For the Third International Consensus Definitions for Sepsis and Septic Shock (Sepsis-3). JAMA 2016;315(8):775-787.

25. Wong $C H$, Khin $L W$, Heng $K S$, et al. The LRINEC (Laboratory Risk Indicator for Necrotizing Fasciitis) score: A tool for distinguishing necrotizing fasciitis from other soft tissue infections. Crit Care Med 2004; 32(7): 1535-41.

26. Schmid MR, Kossmann T, Duewell S. Differentiation of necrotizing fasciitis and cellulitis using MR imaging. Am J Roentgenol 1998; 170(3):615 - 20.

27. Nakamura S, Hashimoto Y, Ishida-Yamamoto A, et al. Hypocalcemia: A sign of severity of necrotizing fasciitis. Dermatology 2004; 209(1):64 - 5.

28. Chelsom J, Halstensen A, Chelsom J, et al. Necrotising fasciitis due to group A streptococci in western Norway. incidence and clinical features. Lancet. 1994; 344(8930):1111-5.

29. Wall DB, Klein SR, Black S, et al. A simple model to help distinguish necrotizing fasciitis from nonnecrotizing soft tissue infection. J Am Coll Surg 2000; 191(3):227 - 31.

30. Stevens DL, Bisno AL, Chambers HF, et al. Executive summary. Practice guidelines for the diagnosis and management of skin and soft tissue infections. 2014 update by the infectious diseases society of America. Clin Infect Dis 2014; 59(2):e10-52.

31. Majeski JA, John JF. Necrotizing Soft Tissue Infections: A Guide to Early Diagnosis and Initial Therapy. Southern Medical Journal 2003; 96(9):900-5.

32. Jabbour G, El-Menyar A, Peralta $R$, et al. Pattern and predictors of mortality in necrotizing fasciitis patients in a single tertiary hospital. World J Emerg Surg 2016; 8;11:40. 
33. Frazee BW, Fee C, Lynn J, et al. Community-Acquired Necrotizing Soft Tissue Infections: A Review of 122 Cases Presenting to a Single Emergency Department Over 12 Years. J Emerg Med 2008; 34(2): $139-46$.

34. Wang YS, Wong CH, Tay YK. Staging of necrotizing fasciitis based on the evolving cutaneous features. International Journal of Dermatology 2007; 46(10):1036-41.

35. Carbonetti F, Cremona A, Carusi V, et al. The role of contrast enhanced computed tomography in the diagnosis of necrotizing fasciitis and comparison with the laboratory risk indicator for necrotizing fasciitis (LRINEC). Radiol Medica 2016; 121(2): 106 - 21.

36. Fayad LM, Carrino JA, Fishman EK. Musculoskeletal infection: Role of CT in the emergency department. Radiographics 2007; 27(6):1723-36.

\section{Figures}




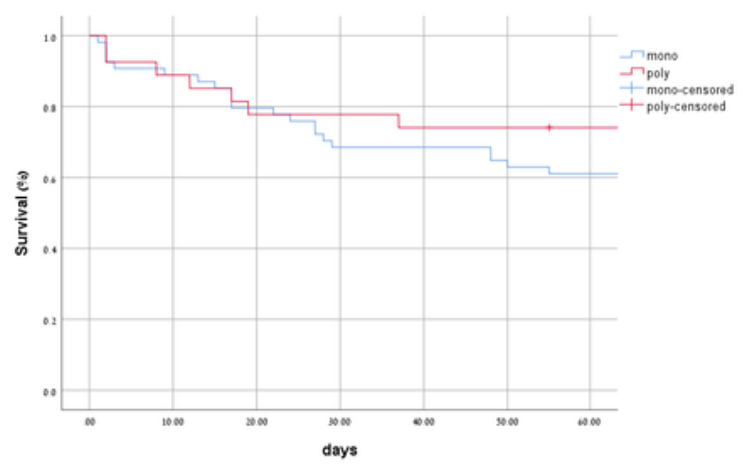

Figure 1. Kaplan-Meire of overall mortality stratified by microbial type $(p=0.23)$

\section{Figure 1}

Kaplan-Meier of overall mortality stratified by microbial type $(p=0.23)$ 